\title{
GIS APPLICATION FOR SOLUTION OF THE PROBLEMS OF PUBLIC TRANSPORTATION SYSTEM IN ZILINA
}

The paper deals with the public transportation system in Zilina. The research study initiated by the Transportation Company of Zilina has been performed with the aim to solve the problems concerning public transportation service in the urban area. The main goal of the research study was to evaluate how well the bus stops serve the public and to identify the segments of the traffic routes, which are risky for buses and trolleybuses operation. Geographic information system was applied to solve these problems by analysing the geospatial data referring to the transportation system. The paper includes the outputs from these analyses.

\section{Defining the problem}

This paper deals with the public transportation system in Zilina. It includes the outputs from the research study "Public Transportation System in the City of Zilina", that has been carried out in the Department of Geotechnics at the Faculty of Civil Engineering since 2002. The research staff of the department has performed the research study with the assistance of two students, who solved some partial problems in their diploma theses. The Transportation Company of Zilina initiated the research study with the aim to solve the problems of public transportation services in the urban area. Although in 1996 the company began with the overall electronisation of the city public transport system and Zilina is the only town in Slovakia, which completely monitors the operation of public transport using on-board computers, there are still several problems that cannot be solved without the assistance of efficient tools providing analyses of geospatial data. One of those tools, geographic information systems (GIS), is becoming more and more familiar to the planners, analysts and researchers as the best way to assess traffic safety, sustainability, and convenience. The main goal of the research study has been to use the tools of GIS for the effective solution of the following problems:

1. To evaluate how well the bus stops serve the public.

2. To identify the segments of the traffic routes, which are risky for buses and trolleybuses operating.

The first problem concerns determination of service coverage of the bus stops, the second one is related to identification of those traffic routes segments that have unsuitable slope of the pavement for operating the public transportation vehicles.

\section{Methodology}

In the urban area of Zilina, the public transportation service is provided by the fixed-route bus and trolley bus system. From the perspective of a bus operator, a basic unit of analysis is a bus-trip. Although varying in format, each bus company maintains a complete list of bus trips for each of several regular schedules (e.g., weekday, weekend days, holiday, etc.). On December 31, 2002 the transportation company employed 400 persons and managed 58 buses and 43 trolley buses. It operated 8 trolley bus and 13 bus lines for a total length of $13.867 \mathrm{~km}$ on workdays. Vehicles are equipped with automatic validation machines for paper tickets and travel chip cards and on-board computers, which store information on vehicle operation. Information is stored in a database and periodically evaluated and analysed with special software. Although this information provides a very useful basis for operational analyses, it is not directly connected with geospatial data.

\section{Network Structure}

A complexity associated with GIS data is the variability of transportation data entities [2]. Transportation entities can have physical description and logical relationships with other transportation entities. They exist both in the real world and virtual world in the database. Since the Department of Geotechnics disposes of the software GIS ArcView 3.1 (without ArcView Network Analyst extension), we decided to use non directed node-arc representation for a planar network model representing the transportation system, however, emerging transportation network models treat multiple modes in a more-sophisticated manner. Within our transportation network, nodes correspond to street intersections and bus stops while arcs correspond to street segments between nodes. The theme of street network was created on the basis of digital map set (scale 1:10 000). The transportation system entities from the real world represent the themes in ArcView in form of points, lines or polygons. Two base themes represent the transportation system: the line theme representing the route network and the point theme representing bus stops were created in the view. The theme of bus stops correctly overlaps the nodes of the line theme (see Fig. 1).

\footnotetext{
* Dana Sitányiová, Soňa Masarovičová

University of Žilina, Faculty of Civil Engineering, Department of Geotechnics, Komenského 52, 01026 Žilina, E-mail: dana.sitanyiova@fstav.utc.sk
} 


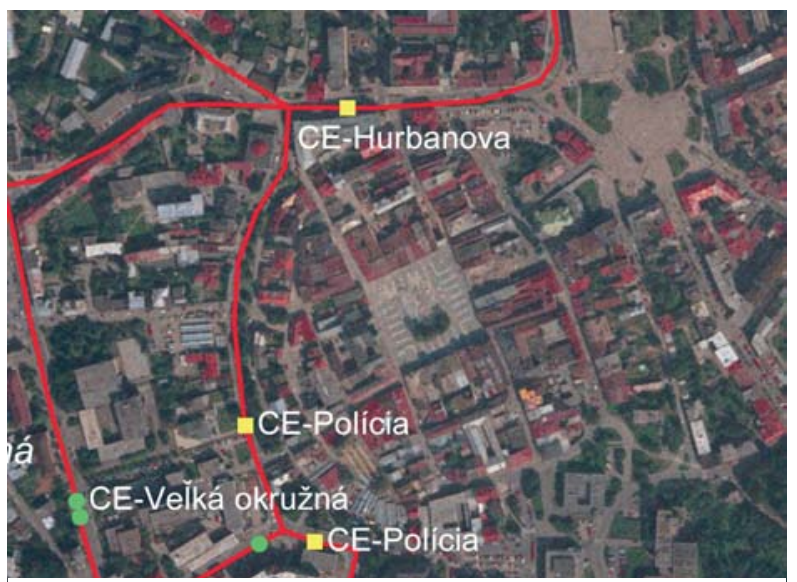

Fig. 1 Street network with the theme of bus stops and route lines.

Focusing on the route-level is common in the case of a fixedroute bus system. In our system the routes have extensive overlaps and carry different route numbers. The bus routes could be considered being separate when specifying a transit route structure. However, these elemental routes should not be digitized independently on a separate GIS theme (layer), but should be defined by reference to the base street network. Provisions should be made so as to be able to combine elemental routes for the preparation route numbering. Partial arcs within the line theme were defined by a route number. It allows a user of the system to identify a route number by a simple click on a street segment.

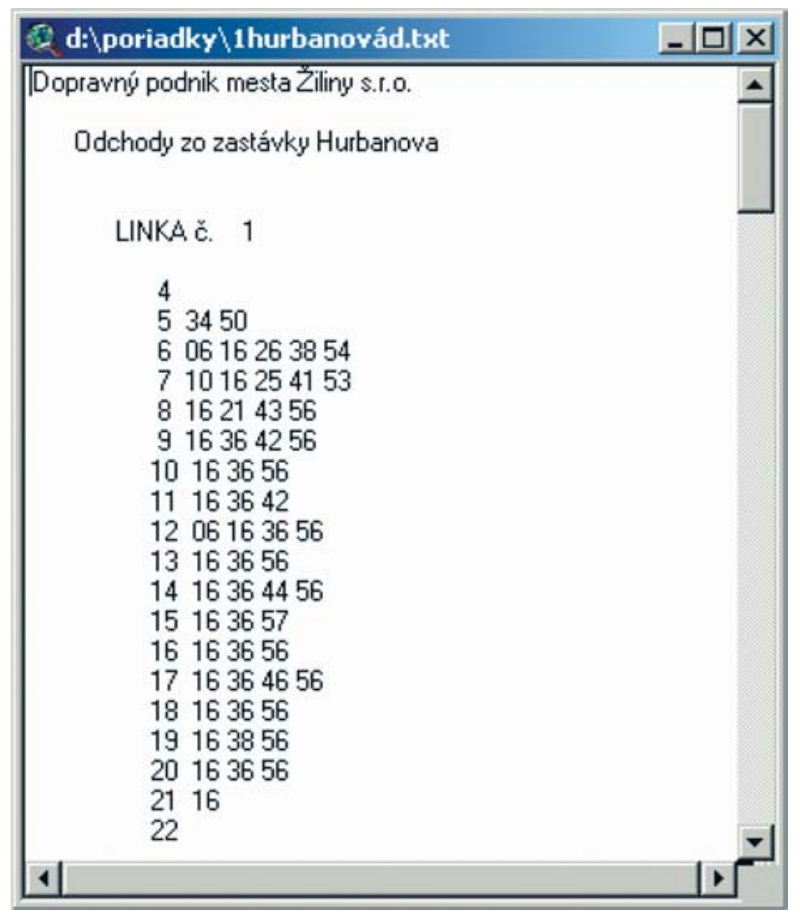

Fig. 2 Time schedule - Hurbanova bus stop (route No. 1).
Spatial entities in GIS ArcView system are connected with attribute data. Attribute data can contain comprehensive information on entity properties. We decided to store information especially about bus stops. The attribute table of bus stops theme includes information on:

- name,

- equipment (ticket machine, shelter construction, news stand, etc.),

- routes available, etc.

Therefore the user of our system is able to obtain information which bus or trolley bus route is available in the bus stop and/or if it is possible to buy a ticket there by clicking on the individual bus stop. The theme of bus stops is linked (ArcView hot link tool) with the external file containing the route timetable (see Fig. 2). Data symbolizing involves choosing the colours and a symbol that will represent a feature. The theme of bus stops can be symbolised by attribute information in several ways. There are bus stops equipped with ticket machines symbolised by yellow squares in Fig. 1. The bus stops without machines are symbolised by green circles. The result is the map showing visual information about the transportation network.

\section{Service Coverage}

Bus stops must be close to where the people who use them live, work or shop. If they take buses, they do not want to walk more than 500 metres to the nearest stop. And the company operating buses does not want its clients to walk very far to use its services.

The location of bus stops and a walking distance to those stops were the concern of the Transportation Company. The simple way how to generate a service coverage of bus stops is to do a circle with a radius 500 metres around it. But that is not sufficient. The circles very often overlap and there are buildings and other objects within their areas. We decided to use analysis tools available in GIS. The process is described step by step and illustrated by figures.

The co-ordinates of the bus stops were determined on the transformed map to the geographical co-ordinates. Distance mapping analysis was made to determine the area of distance. Distance mapping finds how far each cell is from the nearest source. Distance can be measured in term of how far objects are (Euclidean). Two principal groups of analyses utilize the Euclidean system for determining distance: proximity mapping and distance mapping. We decided to use the combination of both. The analysis is described as follows step by step. At first the analysis of distance was carried out. Since walking distance to the bus stop should be 500 metres, only the cells within 500 metres of the selected bus stops (four bus stops in the town centre) were symbolised by red colour (see Fig. 3).

Then the analysis of proximity was made with the aim to assign which bus stop serves to which cells (service area). Fig. 4 represents the combination of the analyses in the limited area. 


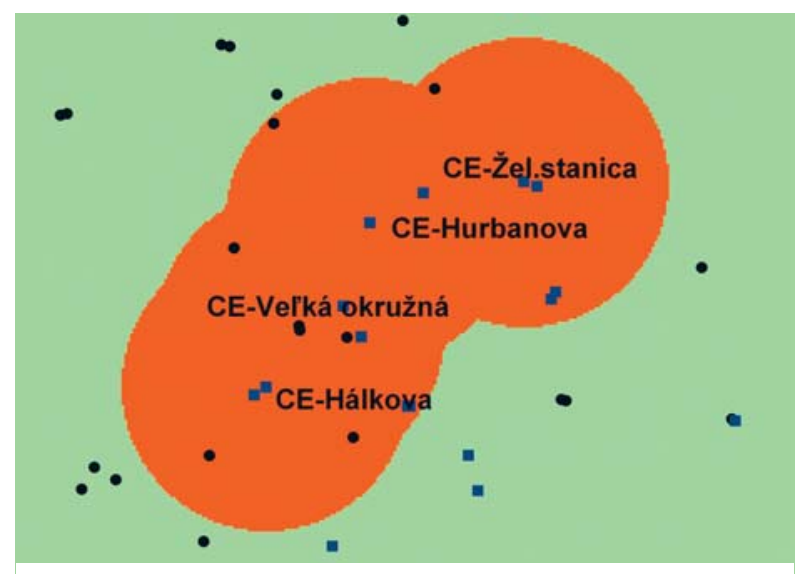

Fig. 3 Distance analysis on the four bus stops in the town centre.

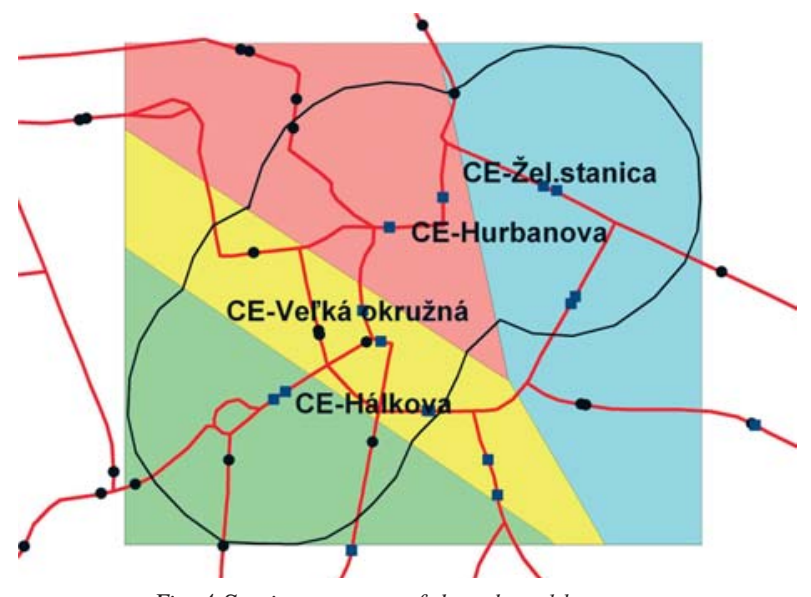

Fig. 4 Service coverage of the selected bus stops.

This combined analysis was made for all the bus stops in the town. It is also possible to include certain other parameters, which can be taken into account in the analysis. The importance of these parameters can be assigned based on the requirements of a public and/or transportation operator. As parameters we can consider:

- importance of locations such as hospitals or schools,

- density of population,

- time,

- availability of infrastructure and finance,

- traffic congestion,

- other modes of transport, etc.

\section{Risk analysis for bus and trolley bus operating}

Bus and especially trolley bus operating requires special conditions in term of infrastructure. The limited slope of the pavement is needed for smooth operation of vehicles. The slope below $12 \%$ is required for bus operating and $15 \%$ for trolley bus operating. Therefore, the Transportation Company required identifying those routes segments that have unsuitable slope of the pavement for the operating of the public transportation vehicles. Since the risk slope analysis is principally made up of surface, the analysis of surface elevation was made with the aim to solve this problem. A surface has steepness and direction, commonly referred to as slope and aspect. The Derive Slope choice on the surface menu in GIS ArcView can take a grid or TIN theme as input. The grid theme represents surface using a mesh of regularly spaced points. TIN (triangulated irregular network) represents surfaces using contiguous triangle facets. Since the lines (contours) were available as a source of information about elevation, we decided to use TIN to represent the surface (See Fig. 5).

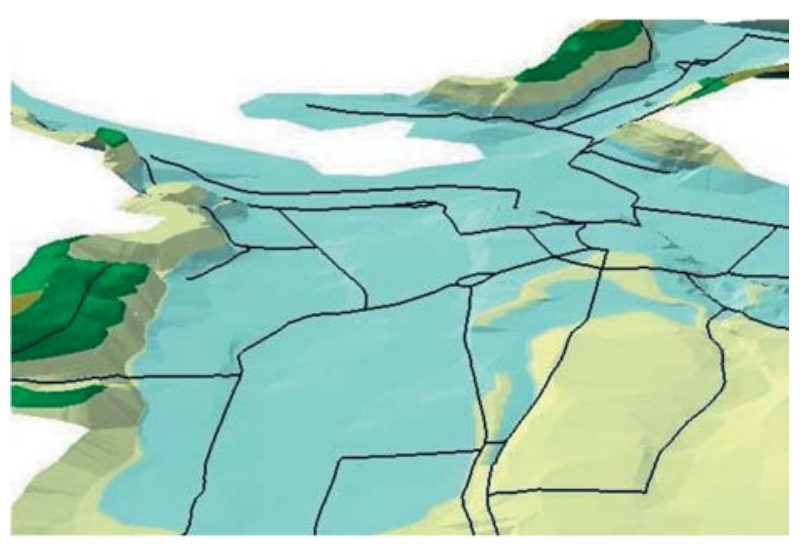

Fig. 5 3D scene with TIN representing the elevation with the bus routes [1].

The slope identifies the incline of a surface. The output slope theme can represent a slope in degrees or percentages. We have derived the slope map from TIN theme. There are two possibilities how to identify the areas with an unsuitable slope (15\% for trolley buses):

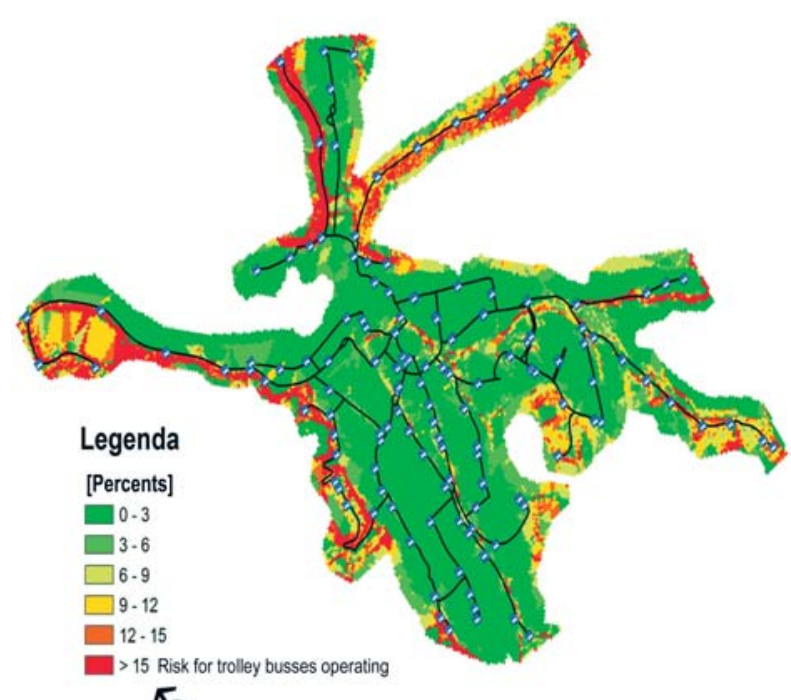

视

Fig. 6 The map of a risk slope - trolley buses [1]. 
1. to reclassify the slope map on three classes $(<15 \%,>15 \%$, no data), or

2. to query the slope map theme (find areas with adverse slope $>15 \%)$

We used the latter possibility. The output is represented by GRID - risk map, where the areas with the risk slope are represented by red colour (See Fig. 6). There are several parts of the

Profile graph - route No. 3

Direction: Solinky - Železničná stanica - Spanyolova Vertical exaggeration $50 x$

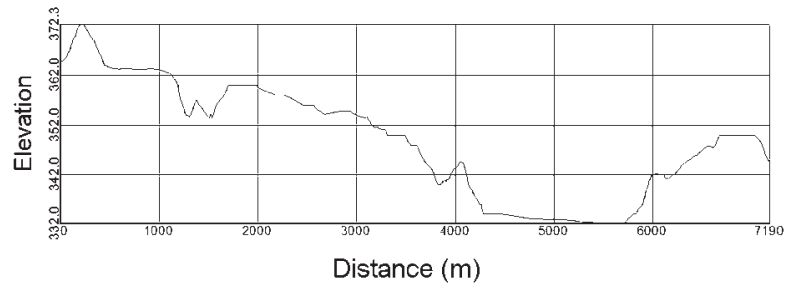

Fig. 7 Profile graph for the route No. 3 [1]. routes within areas with an adverse slope (Hájik, Zástranie, Zilinská Lehota, etc.) In addition, the set of profile graphs for each route was created (See Fig. 7)

\section{Conclusions}

The study of public transportation system issues of Zilina was carried out by means of advanced methods of data analysis such as the use of GIS for the spatial analysis, which offers the following advantages:

- use of geospatial referenced data,

- graphical and attribute data input and editing,

- spatial and attribute query,

- advanced visualization, etc.

This way GIS can be used in all the ways to carefully analyse all the public transportation problems and to successfully give a good solution that is acceptable for everyone. GIS can also encourage a holistic approach to transportation analysis, supporting integrated analysis of transportation system components within its geospatial context.

\section{References}

[1] KONEČNÝ, A.: Application of GIS for profile graph analysis of public transportation routes in Zilina (in Slovak), Thesis, 2003.

[2] HARVEY, J. M., SHIH-LUNG, SH.: Geographic Information Systems for Transportation, Oxford University Press, 2001. 